\title{
Políticas de inclusão escolar: um estudo sobre a classe hospitalar no Brasil
}

\author{
School inclusion policies: a study about the hospital class in Brazil \\ Politicas de inclusión escolar: un estudio sobre la clase hospitalaria en Brasil \\ RICARDO ANTONIO GONÇALVES TEIXEIRA \\ UYARA SOARES CAVALCANTI TEIXEIRA \\ MÁRIO JOSÉ DE SOUZA \\ PEDRO PAULO PEREIRA RAMOS
}

Resumo: Este estudo objetiva apresentar um quadro teórico, metodológico e documental das produções científicas sobre classes hospitalares no Brasil. Caracteriza-se como estudo bibliográfico, valendo-se do método de Revisão Sistemática. Como resultados, apresenta a predominância da pesquisa qualitativa como metodologia de estudo; a proveniência de publicações vinculadas a instituições federais de ensino; recorrência de estudos focados em atividades de formação docente e sondagem sobre percepção de acompanhantes a respeito de atendimentos pedagógicos realizados no âmbito hospitalar. Contribui com uma matriz de referência teórico-documental, servindo de base para estudos sobre o tema.

Palavras-chave: Educação especial; políticas da classe hospitalar; atendimento pedagógico hospitalar e domiciliary; revisão sistemática.

\begin{abstract}
This article proposes to present a theoretical, methodological and documental framework in the scientific production about the hospital classes in Brazil. It is characterized as a bibliographical study, using the Systematic Review method. As a result, it presents the predominance of qualitative research as study methodology, the provenance of publications related to federal institutions of teaching, predominance of studies focused on training teachers and survey on perception of family, and accompanying the pedagogical care provided in hospitals. This paper contributes to the consolidation of an array of theoretical and documentary reference, providing the basis for studies on the subject.
\end{abstract}

Keywords: Special education; hospital class policies; hospital and home educational services; systematic review.

Resumen: Este estudio tiene como objetivo presentar un marco teórico, metodológico y documental de las producciones científicas sobre clases hospitalarias en Brasil. La investigación se caracteriza como estudio bibliográfico valiéndose del método de Revisión Sistemática. Como resultados, presenta el predominio de la investigación cualitativa como metodología de estudio; la 
procedencia de publicaciones vinculadas a instituciones educativas federales; recurrencia de estudios que se centraron en las actividades de formación del profesorado y sondeo sobre la percepción de acompañantes acerca de la atención pedagógica realizada en los hospitales. Contribuye con una una matriz de referencia teórico y documental, sirviendo de base para estudios sobre el tema.

Palabras clave: Educación especial; políticas de clase hospitalaria; atención pedagógica hospitalaria y en domiciliaria; revisión sistemática.

\section{INTRODUÇÃO}

Este estudo elege como tema a classe hospitalar, uma modalidade de ensino decorrente da educação especial na perspectiva de inclusão escolar. As perguntas norteadoras do estudo são: quais as principais políticas públicas que subsidiam a classe hospitalar no Brasil? Como se compõe a produção de conhecimento nessa área? Quais as principais referências que fundamentam as pesquisas publicadas? Como forma de responder ou tangenciar as questões de investigação, propõe-se, como objetivo, compor um quadro teórico, metodológico e documental contemplado nos artigos publicados. Para tanto, baseou-se em um estudo exploratório, bibliográfico, valendo-se do método de Revisão Sistemática. Como fonte, conforme detalhado no capítulo "Método", pesquisaram-se, em duas bases de indexação, tendo como descritores utilizados na busca dos artigos, as expressões: "classe hospitalar", "atendimento pedagógico hospitalar", "escola hospital", "pedagogia hospitalar" e "escolarização em hospitais".

Para a análise dos dados, em uma perspectiva mista, utilizaram-se como suporte o software NVivo, versão 11, para as análises qualitativas, e o pacote estatístico SPSS, versão 23, para as análises quantitativas.

Como resultados, a análise dos artigos selecionados conduziu ao perfil das produções acerca dos atendimentos pedagógicos hospitalares e domiciliares no tocante a número, veículo e período de produção, ao contexto institucional e regional dos autores, bem como aos objetivos e referências adotados no interior dos produtos em análise.

\section{CLASSES HOSPITALARES: PRINCÍPIOS E BASES POLÍTICAS}

O atendimento educacional hospitalar e domiciliar, também denominado de classe hospitalar, segundo definição dada pelo Ministério da Educação, constitui-se como modalidade de atendimento a alunos que, por motivo de tratamento de saúde, são impedidos de frequentar a sala de aula comum do ensino regular (BRASIL, 2002). 
Esse atendimento está baseado na percepção de que o adoecimento está entre as situações que afastam os educandos da escola, permanente ou temporariamente, e, sendo a escolarização uma premissa legal, esta não pode ser interrompida durante o período de internação.

De acordo com Fonseca (1999), o Hospital Municipal Jesus, no Rio de Janeiro, acolhe a mais antiga classe hospitalar de que se tem registro no Brasil, cujas atividades tiveram seu início no ano de 1950. Alguns pesquisadores consideram que os primeiros atendimentos ocorreram em São Paulo, na década de 1930, porém, de acordo com Albertoni (2014), os registros escolares indicam que as classes hospitalares começaram na Santa Casa da Misericórdia, em 1953.

No entanto, apesar de a legislação brasileira regular essa modalidade de atendimento há mais de uma década, o que se verifica é sua tímida presença em ambientes de tratamento de saúde. Fato semelhante ocorre em relação aos estudos sobre o tema. O número de publicações científicas brasileiras que aborda o atendimento pedagógico em hospitais e domicílio é reduzido, quando comparado à necessidade de conhecimento sobre essa temática.

Esse cenário tem mantido o desconhecimento acerca do direito garantido a crianças, jovens e adultos de não terem sua escolarização interrompida em virtude do adoecimento, como também tem impedido que a integralidade do tratamento de saúde seja disponibilizada durante o período de hospitalização.

Em termos de garantias, a educação como um preceito constitucional é direito social de todo cidadão $\left(\operatorname{art.} 6^{\circ}\right.$ ), sendo o poder público responsável por promovêla (art. 23; art. 205), tendo o Plano Nacional de Educação a função de buscar a universalização do atendimento escolar (BRASIL, 1988).

Partindo dos princípios constitucionais sobre o direito à educação, a garantia de atendimento pedagógico a estudante impossibilitado de frequentar a escola passa a ganhar força com desdobramento em outras instâncias legais.

Com base no Estatuto da Criança e do Adolescente (ECA), que contempla, em seu art. 53, o direito à educação da criança e do adolescente (BRASIL, 1990), em 1995, a Sociedade Brasileira de Pediatria elabora um documento em defesa dos direitos da criança e do adolescente, expressa pela Resolução n. 41/1995, do Conselho Nacional dos Direitos da Criança e do Adolescente (CONANDA), que institui o direito da criança e do adolescente ao "acompanhamento do curriculum escolar durante sua permanência hospitalar” (CONANDA, 2004, p. 59).

Embora o referido atendimento não tenha sido explicitado na Lei de Diretrizes e Bases da Educação (LDB), Lei n. 9.394/96, o artigo 5º parágrafo $\mathrm{V}$, e o artigo 23, reafirma as bases constitucionais de garantia da obrigatoriedade de ensino, atribuindo ao poder público a responsabilidade da criação de formas alternativas de acesso aos diferentes níveis de ensino. As garantias de atenção 
especial se valem do preceito da organização de meios e formas de contemplar tais prerrogativas, sempre que o interesse do processo de aprendizagem recomendar (BRASIL, 1996).

Em termos de marco político, foi por meio do Decreto no 3.298/1999, instituindo a primeira política de educação especial pós-LDB (Política Nacional para a Integração da Pessoa Portadora de Deficiência), que as bases para o atendimento a educandos em tratamento de saúde se constituiu. A política de educação especial, embora se intitule para pessoa com deficiência, amplia o entendimento acerca das obrigações do poder público na demanda de atenção à educação especial.

A terminologia adotada no documento, necessidades educacionais especiais, é compreendida, conforme art. 24, inciso VI, parágrafo $1^{\circ}$, como "modalidade de educação escolar oferecida preferencialmente na rede regular de ensino para educando com necessidades educacionais especiais, entre eles o portador de deficiência”. A ideia de indicar a preferência da oferta de ensino na rede regular de ensino surge como contraposição ao modelo de ensino especial nos moldes segregacionistas, praticado por instituições filantrópicas especializadas em deficiência, como é o caso das APAE, Pestalozzi, que se multiplicaram nas décadas de 1960 e 1970 em todo o país.

Quanto às necessidades educacionais especiais, compreende-se que entre o público a ser contemplado pela política - educandos com deficiência - há uma ampla perspectiva de atendimento, dentre os quais inserem-se os educandos impedidos de frequentar a escola por motivo de doença ou convalescença.

As Diretrizes Nacionais para a Educação Especial na Educação Básica, instituídas pela Resolução n ${ }^{\circ}$, de 11 de setembro de 2001, no artigo $3^{\circ}$, define educação especial como uma modalidade da educação escolar, sendo ela

\footnotetext{
Um processo educacional definido por uma proposta pedagógica que assegure recursos e serviços educacionais especiais, organizados institucionalmente para apoiar, complementar, suplementar e, em alguns casos, substituir os serviços educacionais comuns, de modo a garantir a educação escolar e promover o desenvolvimento das potencialidades dos educandos que apresentam necessidades educacionais especiais, em todas as etapas e modalidades da educação básica (BRASIL, 2001).
}

A compreensão da ampla dimensão das necessidades educacionais especiais proposta na política de educação especial é reforçada pela Resolução CNE/CEB $n^{\circ}$ 02/2001. Em seu artigo 13, o princípio da intersetorialidade propõe garantias de acesso à educação do aluno hospitalizado: 
Os sistemas de ensino, mediante ação integrada com os sistemas de saúde, devem organizar o atendimento educacional especializado a alunos impossibilitados de frequentar as aulas em razão de tratamento de saúde que implique internação hospitalar, atendimento ambulatorial ou permanência prolongada em domićlio. (BRASIL, 2001).

O parágrafo $1^{\circ}$ do mesmo artigo usa, pela primeira vez, as expressões classe hospitalar e atendimento em ambiente domiciliar, resumindo suas funções e objetivos:

As classes hospitalares e o atendimento em ambiente domiciliar devem dar continuidade ao processo de desenvolvimento e ao processo de aprendizagem de alunos matriculados em escolas da Educação Básica, contribuindo para seu retorno e reintegração ao grupo escolar, e desenvolver currículo flexibilizado com crianças, jovens e adultos não matriculados no sistema educacional local, facilitando seu posterior acesso à escola regular (BRASIL, 2001).

Desse modo, a Resolução define bases legais para a institucionalização, no âmbito público, das classes hospitalares.

Como forma de estruturar e organizar a política de atendimento pedagógico preconizado pela Resolução CNE/CEB n 02/2001, o Ministério da Educação (MEC) publica, em 2002, o documento "Classe Hospitalar e Atendimento Pedagógico Domiciliar: estratégias e orientações" com o objetivo de aprofundar conhecimentos e orientações acerca do atendimento educacional em hospitais e domiciliares (BRASIL, 2002).

Nesse documento, o MEC define os objetivos do atendimento educacional em ambientes hospitalares e domiciliares:

Cumpre às classes hospitalares e ao atendimento pedagógico domiciliar elaborar estratégias e orientações para possibilitar o acompanhamento pedagógicoeducacional do processo de desenvolvimento e construção do conhecimento de crianças, jovens e adultos matriculados ou não nos sistemas de ensino regular, no âmbito da educação básica e que encontram-se impossibilitados de frequentar escola, temporária ou permanentemente e, garantir a manutenção do vínculo com as escolas por meio de um currículo flexibilizado e/ou adaptado, favorecendo seu ingresso, retorno ou adequada integração ao seu grupo escolar correspondente, como parte do direito de atenção integral (BRASIL, 2002, p. 13).

Em 2008, porém, o MEC, por meio da então Secretaria de Educação Especial (SEESP), instituiu a atual política de educação especial, denominada de "Educação Especial na Perspectiva da Educação Inclusiva" (BRASIL, 2008), ratificada pelo Decreto $\mathrm{n}^{\circ}$ 6.571/2008 (em 2011 o decreto de 2008 foi revogado pelo Decreto $n^{0}$ 7.611/2011). Essa nova política de inclusão assume, explicitamente, a incompetência no contexto de cobertura do atendimento à demanda provocada e 
reduz seu público de atenção aos educandos com deficiência, transtornos globais do desenvolvimento e altas habilidades/superdotação. Embora os preceitos legais garantam o atendimento pedagógico hospitalar/domiciliar em todo território nacional, o fato de a estrutura para esses atendimentos estar ligada à área de educação especial nas secretarias de educação dos estados e municípios brasileiros, os repasses de verbas e recursos passam a ter destinações direcionadas às ações voltadas ao público determinado pela nova política de educação especial.

\section{MÉTODO}

Trata-se de uma pesquisa exploratória, bibliográfica, utilizando-se do método de Revisão Sistemática. A pesquisa, de base mista - qualiquantitativa - utilizou como estrutura de indexação as bases do Portal Periódicos da Coordenação de Aperfeiçoamento de Pessoal de Nível Superior (CAPES) e do Scientific Electronic Library Online (Scielo). Adotaram-se como descritores de busca as expressões: "classe hospitalar", "atendimento pedagógico hospitalar", "escola no hospital", "pedagogia hospitalar" e "escolarização em hospitais".

Como critério de inclusão da publicação no contexto da pesquisa, a amostra foi limitada a artigos científicos com publicações realizadas no período de 2005 a 2016. A pesquisa nas bases, a partir dos descritores de busca, retornou a 173 materiais. No script de busca, utilizaram-se sistemas de filtro a partir do tipo de recurso (artigo), período de publicação (2005 a 2016) e estruturação (periódicos revisados por pares). Após esse processo, a busca retornou um número de 56 artigos, sendo que, desse total, dez publicações encontravam-se em ambas as bases de dados (Capes e Scielo). Desse modo, a amostra inicial se constituiu de 46 publicações.

$\mathrm{Na}$ fase seguinte, procedeu-se ao sistema de leitura de todo material previamente selecionado. O critério de inclusão final dos artigos na pesquisa consistiu no direcionamento dos textos ao campo educacional, tendo como foco o atendimento educacional hospitalar ou domiciliar. A resultante desse processo de leitura retornou ao número de 26 artigos selecionados para o estudo. Destacase que os artigos excluídos abordavam o campo da saúde, sendo direcionados aos seguintes temas: formação de profissionais da saúde, fatores de risco hospitalar, abordagem técnica e terapêutica, morbidade infantil.

O processo de gerenciamento de referência se deu pela utilização do software, plataforma livre, Mendeley Desktop, versão 1.16.3. Como apoio ao processo de análise dos dados, utilizou-se como suporte o software de análise qualitativa NVivo, versão 11, e o pacote estatístico SPSS, versão 23, para as análises quantitativas. 


\section{ANÁLISE DOS ARTIGOS}

A análise das 26 publicações selecionadas levou em consideração o periódico no qual o artigo foi publicado, a instituição de vínculo dos autores e o volume de publicação por ano, dentro do período da revisão. Com relação aos aspectos de conteúdo, foram levantados os objetivos dos estudos, as bases metodológicas de estudo, os referendos legais mais citados nas abras, bem como autores e obras citadas no campo da classe hospitalar.

O Gráfico 1, seguinte, apresenta o volume de publicação de artigos sobre classe hospitalar entre os anos de 2005 e 2016. Observe que o maior número de publicações ocorreu em 2007 e 2011, com a publicação de seis e cinco artigos, respectivamente, sendo que, os demais anos apresentam um volume mais estável de produção. Embora não se verifiquem variações no volume de artigos publicados, o período de 2005 a 2016 passou por mudanças significativas no campo das políticas públicas de atendimento a demandas da educação especial, fator que refletiu expressivamente no formato e número de atendimento no campo hospitalar/domiciliar.

\section{Gráfico 1. Número de publicações por ano}

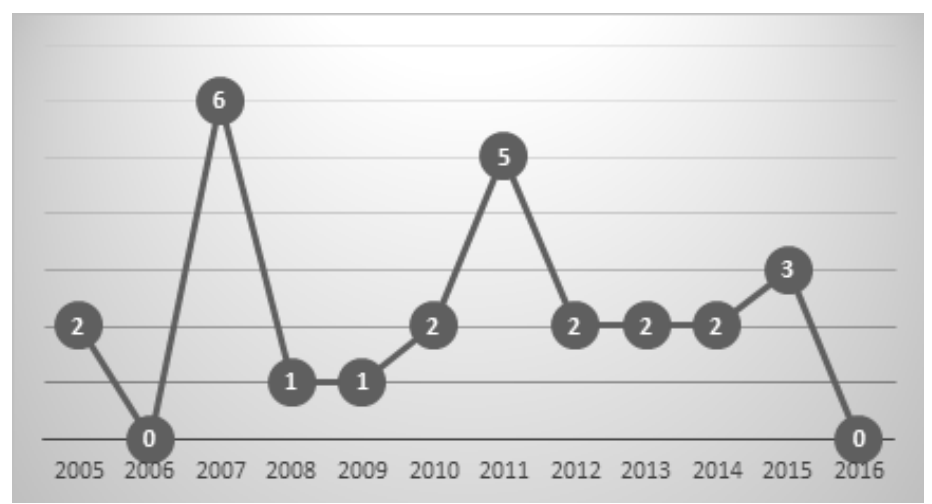

Fonte: dados da pesquisa dos autores

Como exposto, o MEC institui, em 2002, orientado pela política de educação especial de 1999, por meio do Decreto no 3.298, denominada de "Política Nacional para a Integração da Pessoa Portadora de Deficiência” (BRASIL, 1999), que amplia atendimento a educandos com necessidades educacionais especiais, $\mathrm{e}$ pela Resolução CNE/CEB n. 02/2001, que orienta o atendimento a educandos 
em tratamento de saúde, uma política de atendimento pedagógico em ambiente hospitalar e domiciliar por meio do documento intitulado "Classe Hospitalar e atendimento pedagógico domiciliar: estratégias e orientações” (BRASIL, 2002).

Essa política do MEC possibilitou a estruturação e organização dos atendimentos pedagógicos hospitalares e domiciliares em todo país, fator que ampliou significativamente o número de atendimentos a essa demanda.

A partir da nova política de educação especial de 2008, com a redefinição do público de atenção da educação especial, as secretarias de educação deixaram de ser assistidas no campo financeiro e estrutural, o que, em tese, provocou dificuldades na manutenção dos atendimentos educacionais hospitalares e domiciliares, direito garantido aos estudantes em processo de tratamento.

Em termos de meios de divulgação dos artigos analisados, conforme exposto na Tabela 1, as 26 publicações se encontram distribuídas em 19 periódicos distintos, contemplando áreas e enfoques diversos.

Tabela 1. Periódicos de publicação dos artigos da pesquisa e número de publicações

\begin{tabular}{|l|c|}
\hline Título do periódico & N \\
\hline Cadernos CEDES & 3 \\
\hline Revista Psicopedagogia & 2 \\
\hline Revista Brasileira de Educação Especial & 2 \\
\hline Revista Educação Especial & 2 \\
\hline Movimento & 2 \\
\hline Trabalho, Educação e Saúde & 1 \\
\hline Revista Ciência \& Educação & 1 \\
\hline Educação & 1 \\
\hline Revista Educação \& Realidade & 1 \\
\hline Educação e Pesquisa & 1 \\
\hline Educação em Revista & 1 \\
\hline Educar em Revista & 1 \\
\hline Estudos de Psicologia & 1 \\
\hline Linhas Críticas & 1 \\
\hline Revista Brasileira de Crescimento e Desenvolvimento Humano & 1 \\
\hline Revista da Escola de Enfermagem da USP & 1 \\
\hline Revista Psicologia - Teoria e Prática & 1 \\
\hline Revista Texto \& Contexto Enfermagem & 1 \\
\hline Zona Próxima & 1 \\
\hline Total & 1 \\
\hline
\end{tabular}

Fonte: dados da pesquisa dos autores

428 - RBPAE - v. 33, n. 2, p. 421 - 447, mai./ago. 2017 
Os Cadernos CEDES, do Centro de Estudos Educação e Sociedade, que veiculam produções voltadas para a área educacional, apresentaram o maior número de publicações, representando $11,5 \%$ do total do estudo. Ocorrência semelhante se verifica em estudos anteriores, como os de Barros, Gueudeville e Vieira (2011) e Xavier et al. (2013), os quais analisaram períodos outros que não o do presente estudo, porém constataram o mesmo fato em relação ao título de periódico com mais publicações.

Em seguida, temos: Revista Psicopedagogia, Revista Brasileira de Educação Especial, Revista Educação Especial, Movimento e Trabalho, Educação e Saúde, títulos com dois artigos cada, o que equivale a 7,6\% da amostra. Os demais periódicos contêm uma única publicação.

Se considerarmos as revistas por campo de atuação, a distribuição apresenta equilíbrio entre as áreas de Educação, com nove revistas, 13 artigos publicados (50\% das publicações), e Saúde, também com por nove revistas, publicação de 11 artigos (42,3\%), dos quais, dois artigos publicados em dois periódicos da área de psicopedagogia, área de aproximação entre educação e saúde $(7,7 \%)$.

Quanto à vinculação institucional do(s) autor(es) dos artigos, o estudo mostra a presença de 17 instituições de ensino superior, sendo a Universidade Federal de Santa Maria a que apresentou o maior número de artigos publicados com autores a ela vinculados (15,4\%), seguida da Universidade Federal de Santa Catarina (11,4\%). Da mesma forma, como a presença dispersa de periódicos e composição de áreas nas publicações, os estudos se encontram distribuídos em diversas instituições de ensino em todo o Brasil. 
Tabela 2. Instituição de ensino de vinculação do primeiro autor.

\begin{tabular}{|l|l|c|}
\hline Título do periódico & N & $\%$ \\
\hline Universidade Federal de Santa Maria (UFSM) & 4 & 15,4 \\
\hline Universidade Federal de Santa Catarina (UFSC) & 3 & 11,5 \\
\hline Universidade Federal da Bahia (UFBA) & 2 & 7,7 \\
\hline Universidade Federal de Pernambuco (UFPE) & 2 & 7,7 \\
\hline Universidade Federal do Ceará (UFC) & 2 & 7,7 \\
\hline Universidade Federal do Espírito Santo (UFES) & 2 & 7,7 \\
\hline Universidade de Brasília (UnB) & 1 & 3,8 \\
\hline Universidade Federal da Paraíba (UFPB) & 1 & 3,8 \\
\hline Universidade Federal de Campina Grande (UFCG) & 1 & 3,8 \\
\hline Universidade Federal do Tocantins (UFT) & 1 & 3,8 \\
\hline Pontifícia Universidade Católica de São Paulo (PUC-SP) & 1 & 3,8 \\
\hline Universidade Cidade de São Paulo (UNICID) & 1 & 3,8 \\
\hline Universidade de São Paulo (USP) & 1 & 3,8 \\
\hline Universidade Federal de São Carlos (UFSCar) & 3,8 \\
\hline Universidade Federal de São Paulo (UNIFESP) & 1 & 3,8 \\
\hline Universidade Estadual de Ponta Grossa (UEPG) & 1 & 3,8 \\
\hline Universidade Tuiuti do Paraná (UTP) & 1 & 3,8 \\
\hline Total & 1 & 100.0 \\
\hline
\end{tabular}

Fonte: dados da pesquisa dos autores

Quanto à distribuição dos artigos por região, o gráfico seguinte mostra maior concentração na região Sul $(34,6 \%$, sendo a UFSM e UFSC as mais representativas), seguida das regiões Nordeste (30,8\%, sendo a UFBA, UFPE e UFC as mais representativas) e Sudeste (26,9\%, com distribuição dispersa). As regiões Norte e Centro-Oeste apresentaram, cada uma, no período de 2005 a 2016, uma única publicação de artigo vinculada à classe hospitalar. 


\section{Gráfico 2. Percentual de publicações por região do Brasil}

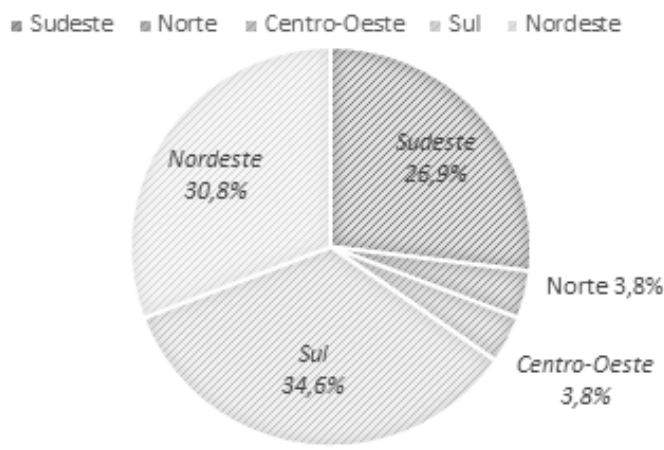

Fonte: dados da pesquisa dos autores

Em função do tipo de instituição, observou-se um predomínio das instituições federais de ensino. As universidades federais, que correspondem a doze das dezessetes instituições de vínculo dos autores, são responsáveis por $80,8 \%$ dos artigos compreendidos no estudo. Já as universidades estaduais respondem por $7,7 \%$ das publicações. As demais, correspondendo aos 11,5\% restantes, são da rede privada, que aparecem em número de três instituições.

No processo de análise dos conteúdos apresentados nos artigos, buscouse apreender os objetivos da pesquisa, o método de investigação, as referências citadas no campo de estudo de classes hospitalares e referendos documentais/ legais mais adotados nos estudos.

No que se refere aos objetivos expressos nos estudos analisados, realizouse uma divisão por abordagens. Elencou-se o objetivo descrito em cada uma das publicações e, em seguida, buscou-se aproximá-los por semelhança de aspectos e escopo. Desse modo, com os objetivos segmentados, foram obtidos seis grupos de abordagens (Tabela 3). 
Tabela 3. Temática dos objetivos, número de artigos e percentual correspondente.

\begin{tabular}{|l|l|l|}
\hline Abordagem dos artigos & N & $\%$ \\
\hline Prática pedagógica na classe hospitalar & 8 & 30,8 \\
\hline Percepção dos sujeitos diretamente envolvidos & 8 & 30,8 \\
\hline Registro de experiências & 3 & 11,5 \\
\hline Aspectos institucionais/administrativos da classe hospitalar & 3 & 11,5 \\
\hline Levantamento de produções sobre classe hospitalar & 2 & 7,7 \\
\hline Instrumentos de ensino/apoio à classe hospitalar & 2 & 7,7 \\
\hline Total & 26 & 100,0 \\
\hline
\end{tabular}

Fonte: pesquisa dos autores

O primeiro grupo, descrito como "Prática pedagógica na classe hospitalar" caracteriza-se por artigos que tiveram por objetivo analisar a formação e a atuação docente na classe hospitalar e atendimento domiciliar. Como expresso na Tabela 3, esse grupo reuniu oito produções (30,8\%). O segundo, denominado "Percepção dos sujeitos diretamente envolvidos", concentrou artigos que objetivavam descrever, sob a ótica dos familiares/acompanhantes e das crianças/ adolescentes hospitalizados, o processo de adoecimento e a influência da classe hospitalar. O terceiro grupo, "Registro de experiências", uniu as publicações que tinham por objetivo divulgar vivências registradas na classe hospitalar. O quarto grupo, nomeado "Aspectos institucionais/administrativos da classe hospitalar" congregou textos que discorriam sobre características referentes à implantação, organização e funcionamento da classe hospitalar.

Encerrando os grupos de abordagens centrais, ambos com dois artigos (7,7\%), designou-se o quinto grupo como "Levantamento de produções sobre a classe hospitalar", que agrupou artigos de revisão de literatura sobre o atendimento pedagógico hospitalar, e o sexto, intitulado "Instrumentos de ensino/apoio à classe hospitalar", compreendeu produções com o objetivo de anunciar ferramentas e mecanismos auxiliadores à ação pedagógica nas classes hospitalares.

Os artigos foram inicialmente classificados segundo o tipo de percurso metodológico aplicado ao estudo, o que pode ser verificado no Gráfico 3, sendo que o método qualitativo (sem definição de procedimento/método) apresentou a maior frequência (34,6\%) entre as publicações. Já a pesquisa-ação, o estudo de caso e a revisão de literatura foram verificados em apenas um artigo cada. 
Gráfico 3. Delineamento metodológico apresentado nas publicações ${ }^{1}$

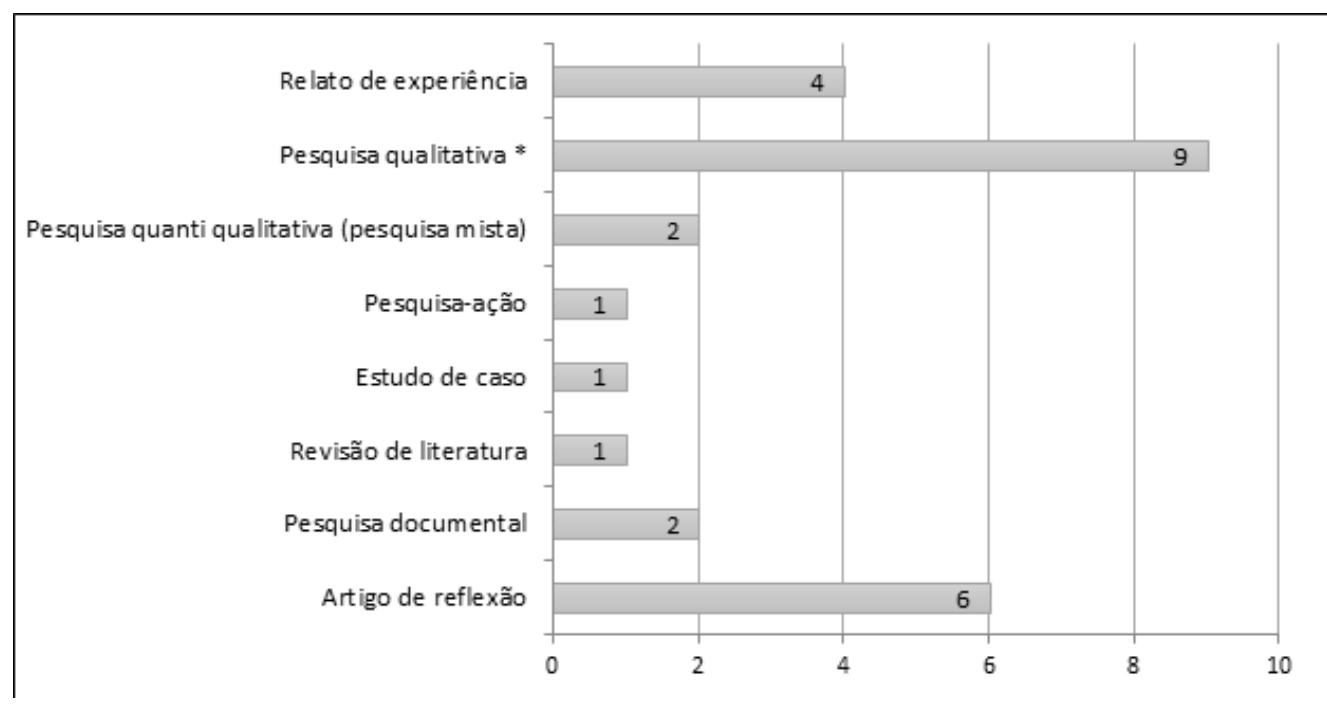

Fonte: dados da pesquisa dos autores

Sobre a falta de indicação de métodos/procedimentos metodológicos nos caminhos da investigação, estudos de André (2000; 2001) e Gatti (2000) apontam falta de rigor e fragilidade no trato metodológico e nas técnicas de investigação nos estudos no campo da educação. O número reduzido de sujeitos e espaços de estudo, bem como falta de clareza e superficialidade na composição do método, falta de parâmetro teórico, sem descrição clara do procedimento, têmse caracterizado como uma constante nas produções na área de educação.

É importante ressaltar a dificuldade de sintetizar o contexto das obras e suas abordagens somente pelo critério de leitura e análise dos textos individualmente. As técnicas apresentadas, proporcionam um cruzamento sintético entre o lido, percebido, registrado com o estruturado e organizado. Não se trata de uma análise puramente métrica-estatística, mas de um cruzamento intencional entre as dimensões do percebido e o estruturado. Dessa feita, apresentam-se algumas tentativas de estruturação das obras analisadas, sem perder de vista a composição da análise qualitativa dos textos.

A partir da técnica de Nuvem de Palavras, exposta na Figura 1, em que as palavras mais recorrentes são apresentadas em maior dimensão, em uma busca pelas 1.000 palavras mais frequentes nos 26 artigos em estudo (retirando classes

1 Pesquisa qualitativa sem definição de procedimento/método 
gramaticais como substantivos, adjetivos, pronomes, numerais, dentre outros), tem-se a presença destacada de termos como hospitalar, educação, classe, crianças, saúde.

Figura 1. Nuvem de palavras mais frequentes nos artigos em estudo

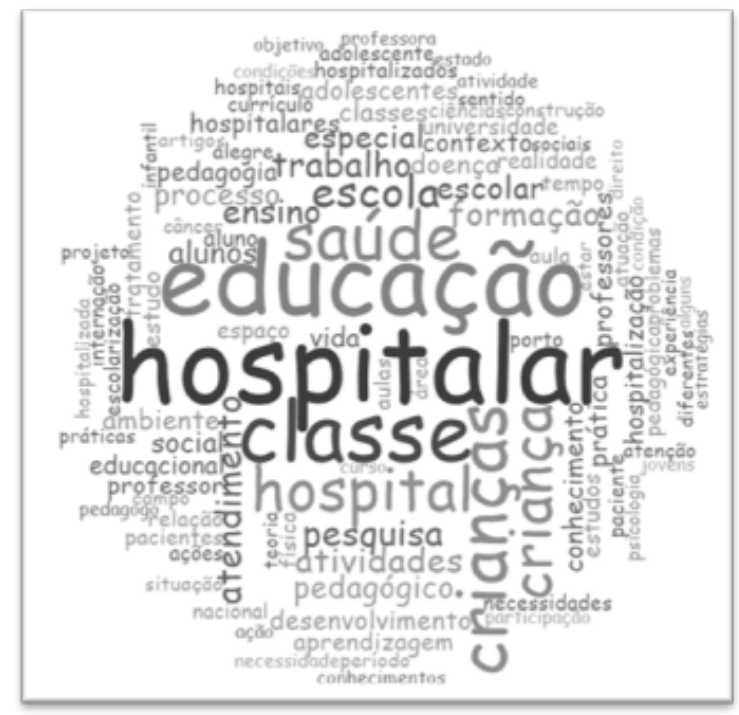

Fonte: Dados da pesquisa dos autores

Em um processo de hierarquização das palavras mais frequentes, observa-se, pelo Gráfico 4, a maior concentração das citações nas sete primeiras palavras, ou seja $61,4 \%$ das citações em apenas 35\% do total de 20 palavras mais recorrentes. 
Gráfico 4. Composição gráfica das 20 palavras mais frequentes nos 26 textos analisados

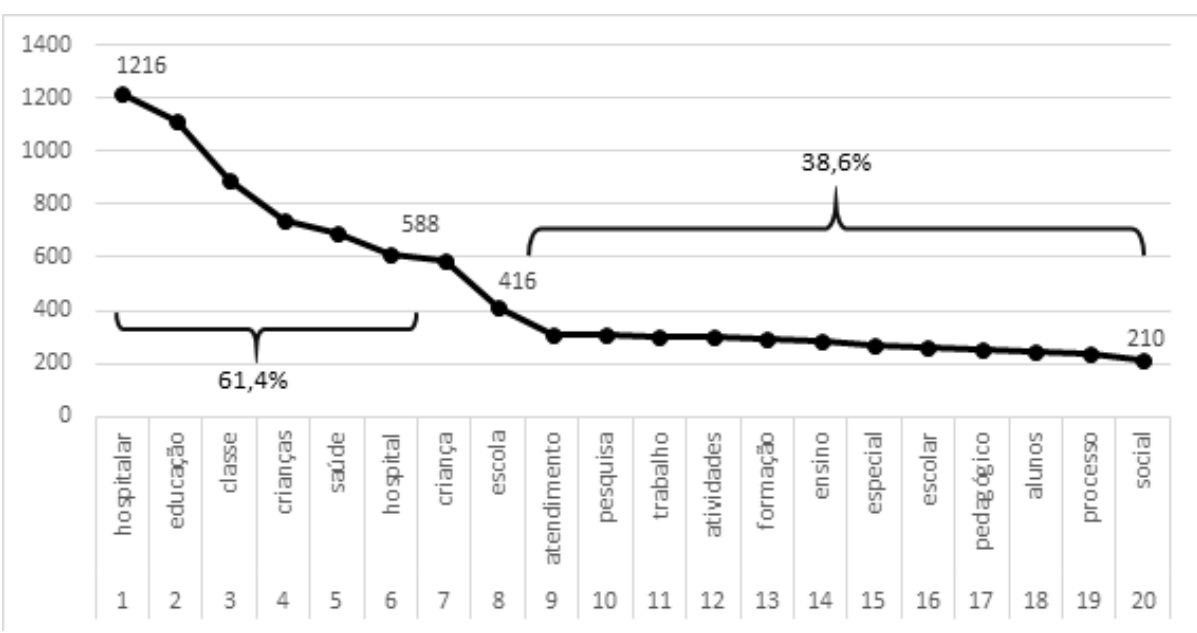

Fonte: Dados da pesquisa

Elaboração: os autores

Na perspectiva de Bauer e Gaskell (2002), mesmo em grandes amostras, o número de palavras relevantes raramente excederá a 20. Para ele,

Por mais radical que possa parecer o fato de reduzir uma lista de 1.000 palavras, ou mais, a uma lista de apenas pouco mais ou menos de 20, esse é um passo necessário se quisermos descobrir campos de coocorrência de palavras. Quanto menos frequente uma palavra, menos provável que um número razoável de contingências com outras palavras possa ser observado na amostra (p. 424).

Reitera-se, neste estudo, o uso métrico proposto pela análise estatística, combinado com uma análise textual a priori.

$\mathrm{Na}$ busca por ligação dessas palavras ao contexto de aplicação, buscouse, com a Análise de Cluster ou aproximações de blocos de palavras, a partir do Coeficiente de Correlação de Pearson, a composição por aproximações de ideias e sentidos. 
Figura 2. Análise de cluster das 20 palavras mais frequentes nos 26 textos, a partir do Coeficiente de Correlação de Pearson

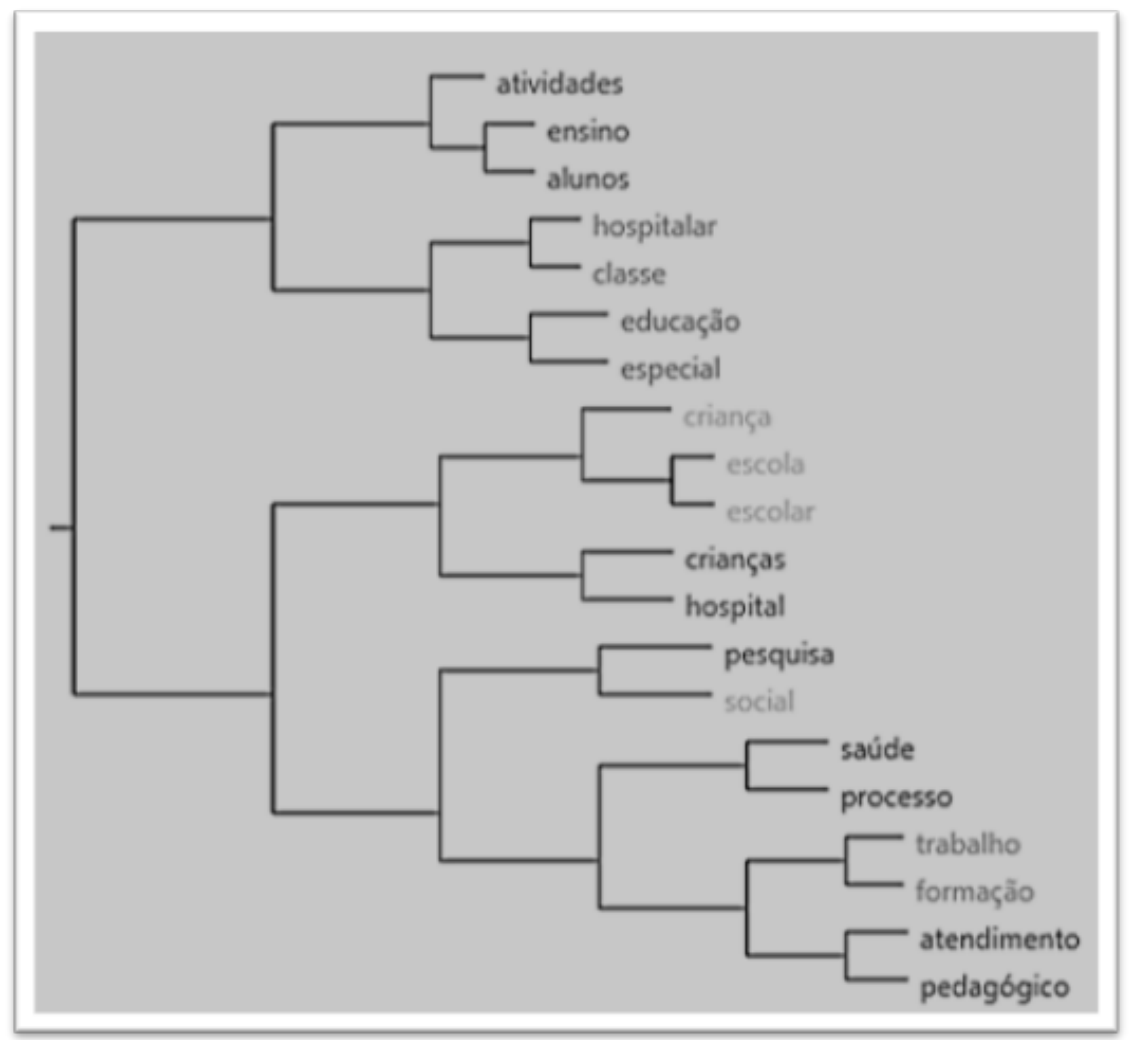

Fonte: Dados da pesquisa dos autores

Em cada uma das dez ramificações proporcionadas no conglomerado (cluster), conforme Figura 2, as ligações se aproximam ou se distanciam. Nas ramificações superiores, observa-se que as atividades estão conectadas a duas áreas de congruência, ou seja, ao ensino e alunos, o que indica que, nos 26 artigos em análise, o processo de atividade no campo hospitalar/domiciliar tem aproximação direta com as duas dimensões indicadas.

Na ramificação subsequente, há uma ligação ou concorrência textual direta entre os aspectos hospitalares e a classe, sentido que se verifica na constituição dos critérios de elegibilidade dos artigos, ou seja, a base-filtro dos artigos selecionados no âmbito do estudo. Os artigos que apresentavam estudos hospitalares não ligados ao campo da educação foram retirados do contexto de análise para o presente estudo. 
$\mathrm{Na}$ composição do cluster, há a opção de aproximação de palavras pela semelhança, raiz ou por sinônimos. Optamos por não fazer nenhum tipo de aproximação, no cuidado de não recair no risco de aproximações incongruentes e dissonantes. A exemplo disso, na Figura 2, a raiz criança encontra-se ligada a dois termos semelhantes: escola e escolar, com número de citações relevantes (416 e 261, respectivamente, conforme Gráfico 4), fator que reforça aproximações nos textos da presença de crianças em sua relação com o contexto escolar, recortado, na árvore seguinte, no âmbito hospitalar.

São relevantes também, na análise de cluster, a relação estabelecida da pesquisa a partir de um contexto social; a saúde enquanto processo; bem como o trabalho, em linhas paralelas, ligado ao processo de formação a partir de atendimentos no campo pedagógico.

As análises em Nuvens de Palavras e em cluster podem ser melhor percebidas, em termos de proporções geométricas, por meio do Mapa de Árvore, indicado na Figura 3.

Figura 3. Mapa de Árvore das 20 palavras mais frequentes dos textos em análise

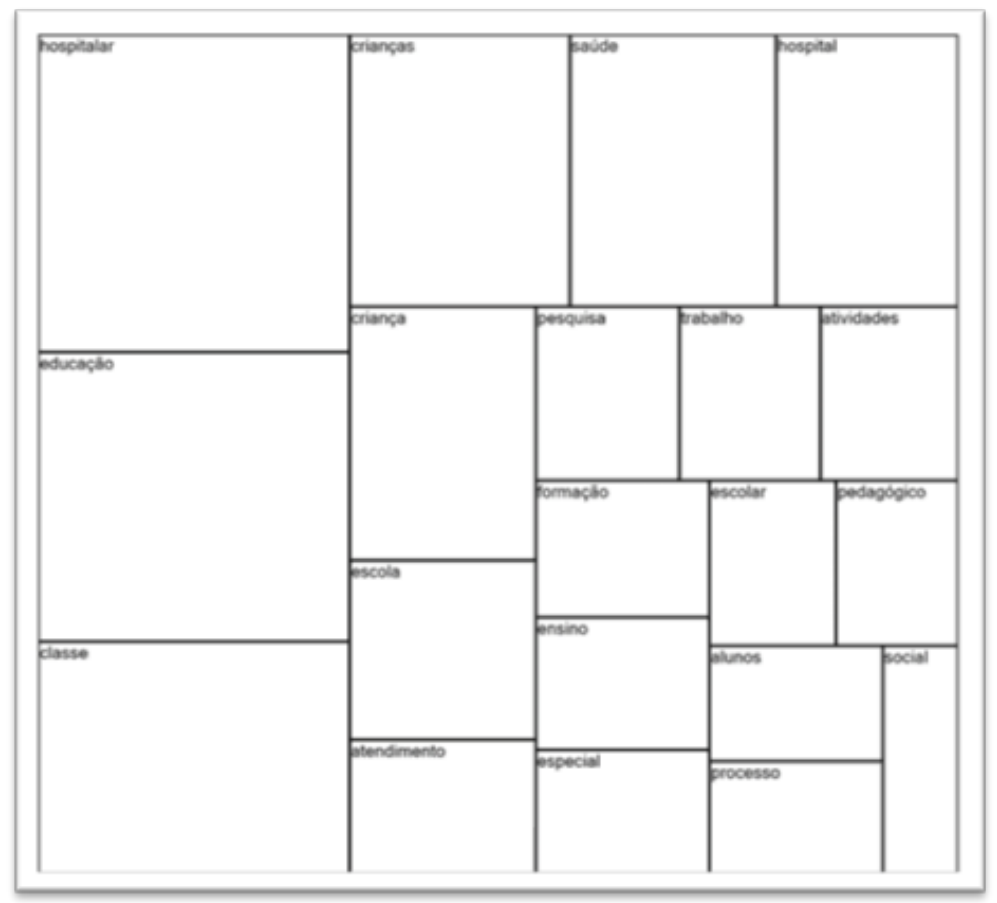

Fonte: Dados da pesquisa dos autores 
Em relação aos autores citados nos artigos, buscou-se realizar um levantamento dos autores e obras mais recorrentes nas publicações analisadas. Optou-se, no cômputo de autoria, por contabilizar uma única citação do mesmo autor, mesmo que fosse mencionado em mais de uma obra de sua autoria na referência.

Desse modo, registraram-se todos os autores citados nos estudos da revisão, contabilizando um total de 369. Dentre esses, levantou-se o número de artigos que se utilizaram desses autores. Mais de $80 \%$ deles (304) foram citados apenas uma vez. Os demais (65) estiveram presentes em mais de uma obra. Um deles, citados em 20 dos 26 artigos da revisão.

Os nove autores mais citados estão descritos na Tabela 4. Eneida Simões da Fonseca é a autora mais citada nos artigos da revisão, destacando-se, dentre suas produções, os artigos intitulados "Implantação e implementação de espaço escolar para crianças hospitalizadas" e "Atendimento escolar no ambiente hospitalar", publicados em 2002 e 2003, respectivamente (ver referências na Tabela 5). Um dado complementar observado durante a pesquisa é a titulação apresentada por cada um desses autores: todos os nove possuem doutorado, sendo seis em Educação, um em Saúde Pública, um em Ciências Sociais e um em Psicologia.

Tabela 4. Autores mais citados nos artigos em análise

\begin{tabular}{|c|c|c|}
\hline Autores & N & $\%$ \\
\hline FONSECA, E. S. (Eneida Simões da Fonseca) & 20 & $76,9 \%$ \\
\hline CECCIM, R. B. (Ricardo Burg Ceccim) & 12 & $46,2 \%$ \\
\hline BARROS, A. S. S. (Alessandra Santana Soares Barros) & 8 & $30,8 \%$ \\
\hline ORTIZ, L. C. M. (Leodi Conceição Meireles Ortiz) & 8 & $30,8 \%$ \\
\hline FREITAS, S. N. (Soraia Napoleão Freitas) & 7 & $26,9 \%$ \\
\hline PAULA, E. M. A. T. (Ercilia Maria Angeli Teixeira de Paula) & 7 & $26,9 \%$ \\
\hline FONTES, R. S. (Rejane de Souza Fontes) & 6 & $23,1 \%$ \\
\hline MATOS, E. L. M. (Elizete Lucia Moreira Matos) & 5 & $19,2 \%$ \\
\hline MINAYO, M. C. S. (Maria Cecilia de Souza Minayo) & 4 & $15,4 \%$ \\
\hline
\end{tabular}

Fonte: pesquisa dos autores

As referências completas das obras citadas mais de uma vez no corpo do trabalho se encontram disponibilizada na Tabela 5. 
Tabela 5. Obras mais citadas nos textos em análise

\begin{tabular}{|c|c|}
\hline Referências & $\begin{array}{l}\text { Número } \\
\text { de artigos } \\
\text { presentes }\end{array}$ \\
\hline FONSECA, E. S. Atendimento escolar no ambiente hospitalar. São Paulo: Memnon, 2003. & 12 \\
\hline $\begin{array}{l}\text { FONSECA, E. S. Implantação e implementação de espaço escolar para crianças hospitalizadas. } \\
\text { Revista Brasileira de Educação Especial, Marília, v.8, n.2, p.205-222, } 2002 .\end{array}$ & 5 \\
\hline $\begin{array}{l}\text { FONSECA, E. S. A situação brasileira do atendimento pedagógico-educacional hospitalar. } \\
\text { Educação e Pesquisa, São Paulo, v. } 25 \text {, n. 1, p. 117-129, } 1999 .\end{array}$ & 4 \\
\hline $\begin{array}{l}\text { CECCIM, R. B. Criança hospitalizada: a atenção integral como uma escuta à vida. In: CECCIM, R. } \\
\text { B.; CARVALHO, P. R. A. (Org.). Criança hospitalizada: atenção integral como escuta à vida. Porto } \\
\text { Alegre: UFRGS, 1997. p. 27-41. }\end{array}$ & 4 \\
\hline $\begin{array}{l}\text { FONTES, R. S. A escuta pedagógica à criança hospitalizada: discutindo o papel da educação no } \\
\text { hospital. Revista Brasileira de Educação, São Paulo, n. 29, 2005, p. 119-138. }\end{array}$ & 4 \\
\hline $\begin{array}{l}\text { MATOS, E.L.M.; MUGIATTI, M.M.T.F. Pedagogia hospitalar: a humanização integrando educação } \\
\text { e saúde. Petrópolis: Vozes, } 2006 \text {. }\end{array}$ & 4 \\
\hline $\begin{array}{l}\text { FONSECA, E. S.; CECCIM, R. B. Atendimento pedagógico-educacional hospitalar: promoção do } \\
\text { desenvolvimento psíquico e cognitivo da criança hospitalizada. Temas sobre desenvolvimento, } \\
\text { São Paulo, v. } 7 \text {, n. 42, p. 24-36, } 1999 \text {. }\end{array}$ & 3 \\
\hline $\begin{array}{l}\text { CECIM, R. B. Classe hospitalar: encontros da educação e da saúde no ambiente hospitalar. Pátio } \\
\text { - Revista Pedagógica, Porto Alegre, v. 3, n. 10, p. 41-44, } 1999 .\end{array}$ & 3 \\
\hline $\begin{array}{l}\text { BARROS, A. S. S. Contribuições da educação profissional em saúde à formação para o trabalho } \\
\text { em classes hospitalares. Cadernos Cedes, Campinas, v. } 27, \text { n. } 73 \text {, p. 257-278, } 2007 .\end{array}$ & 3 \\
\hline $\begin{array}{l}\text { ORTIZ, L. C. M. Classe hospitalar: um olhar sobre sua práxis educacional. Revista Brasileira de } \\
\text { Estudos Pedagógicos, v.82, n.200/201/202, p.70-77, jan/dez. } 2001 \text {. }\end{array}$ & 3 \\
\hline $\begin{array}{l}\text { CECCIM, R. B. Criança hospitalizada: a atenção integral como uma escuta à vida. In: CECCIM, R. } \\
\text { B.; CARVALHO, P. R. A. (Org.). Criança hospitalizada: atenção integral como escuta à vida. Porto } \\
\text { Alegre: UFRGS, 1997. p. 27-41 }\end{array}$ & 2 \\
\hline $\begin{array}{l}\text { ORTIZ, L. C. M.; FREITAS, S. N. Classe hospitalar: caminhos pedagógicos entre saúde e } \\
\text { educação. Santa Maria: UFSM, } 2005 \text {. }\end{array}$ & 2 \\
\hline $\begin{array}{l}\text { Minayo M. C. S. O desafio do conhecimento: pesquisa qualitativa em saúde. } 11^{\text {a }} \text { ed. São Paulo/Rio } \\
\text { de Janeiro: Hucitec/Abrasco; } 2009 \text {. }\end{array}$ & 2 \\
\hline $\begin{array}{l}\text { FONTES R. S.As possibilidades da actividade pedagógica como tratamento sócio-afectivo da } \\
\text { criança hospitalizada. Revista Portuguesa de Educação, Braga, v.19, n.01, p.95-128, } 2006\end{array}$ & 2 \\
\hline $\begin{array}{l}\text { FONTES, R. S.; VASCONCELLOS, V. M. R. O papel da educação no hospital: uma reflexão com } \\
\text { base nos estudos de Wallon e Vygotsky. Caderno Cedes, Campinas, v.27, n.73, p.279-303, } 2007 .\end{array}$ & 2 \\
\hline $\begin{array}{l}\text { MINAYO M. C. S. O desafio do conhecimento: pesquisa qualitativa em saúde. } 11^{\text {a }} \text { ed. São Paulo/ } \\
\text { Rio de Janeiro: Hucitec/Abrasco; } 2009\end{array}$ & 2 \\
\hline $\begin{array}{l}\text { MINAYO, M. C. S. (org.). Pesquisa Social: teoria, método e criatividade.7.ed. Petrópolis, RJ: } \\
\text { Vozes,1994. }\end{array}$ & 2 \\
\hline $\begin{array}{l}\text { ZAIAS, E.; PAULA, E.M.A.T. A produção acadêmica sobre práticas pedagógicas em espaços } \\
\text { hospitalares: análises de teses e dissertações. Educação UNISINOS, v.14, n.3, p.222-232, } 2010 .\end{array}$ & 2 \\
\hline
\end{tabular}

Fonte: pesquisa dos autores

Um fator importante a ser destacado é a falta de atualidade das produções referendadas. Embora, para composição dos textos em análise, tenham-se feito recortes de publicações atuais (2005 a 2016), nenhum dos artigos citados nos textos foram publicados no período igual ou inferior a cinco anos. $\mathrm{O}$ mais atual 
dos artigos data de 2011 (Cf. Tab. 5). Em termos de medidas de tendência central, o ano médio de publicação das obras citadas é 2003 (13 anos), a mediana é de 2004 (12 anos), tendo a moda (ano de publicação mais recorrente) o ano de 1999 (17 anos). Em termos de blocos de períodos, observa-se na Tabela 6 um equilíbrio entre os períodos distribuídos em quinquênios das produções citadas no corpo dos textos em análise.

Tabela 6. Autores mais citados, número de artigos em que aparecem e respectivo percentual

Fonte: pesquisa dos autores

\begin{tabular}{|c|c|c|}
\hline Período & $\mathbf{N}^{\mathbf{0}}$ & $\%$ \\
\hline 2012 a 2016 & 0 & $0,0 \%$ \\
\hline 2007 a 2011 & 11 & $30,6 \%$ \\
\hline 2002 a 2006 & 14 & $38,9 \%$ \\
\hline 2001 ou menos & 11 & $30,6 \%$ \\
\hline Total & 36 & $100,0 \%$ \\
\hline
\end{tabular}

Por fim, foi promovida uma busca pelas bases legais/documentais indicadas nos artigos examinados. A Tabela 7 evidencia os principais referendos reportados nas publicações em estudo. O documento mais citado foi "Classe hospitalar e atendimento pedagógico domiciliar: estratégias e orientações", elaborado pelo Ministério da Educação, presente em mais da metade dos artigos explorados. Esse documento traz como objetivo organizar o sistema de atendimento educacional em ambientes hospitalares e domiciliares e estruturar as políticas envolvidas nesse processo (BRASIL, 2002).

Posteriormente, destacaram-se a Política Nacional de Educação Especial (BRASIL, 1994), citada em 38,5\% dos artigos, e a Resolução CNE/CEB no 02, de 11 de setembro de 2001, homologada pela Câmara de Educação Básica do Conselho Nacional de Educação (BRASIL, 2001), também com 38,5\%. Esta última trata das diretrizes em âmbito nacional para alunos com necessidades educacionais especiais (BRASIL, 2001). 
Tabela 7. Documentos e legislações citadas nos artigos e percentual de ocorrência

\begin{tabular}{|l|c|c|}
\hline Documento/Legislação citada nos artigos & $\mathbf{N}^{0}$ & $\%$ \\
\hline $\begin{array}{l}\text { Classe hospitalar e atendimento pedagógico domiciliar: estratégias e orientações. } \\
\text { Secretaria de Educação Especial, 2002. }\end{array}$ & 14 & $53,8 \%$ \\
\hline Política Nacional de Educação Especial. Secretaria de Educação Especial, 1994. & 10 & $38,5 \%$ \\
\hline $\begin{array}{l}\text { Resolução CNE/CEB n. 02, de 11/09/2001. Institui as Diretrizes Nacionais para a } \\
\text { Educação Especial na Educação Básica. }\end{array}$ & 10 & $38,5 \%$ \\
\hline $\begin{array}{l}\text { Resolução n. 41 de 13/10/1995. Conselho Nacional dos Direitos da Criança e do } \\
\text { Adolescente. }\end{array}$ & 8 & $30,8 \%$ \\
\hline Lei de Diretrizes e Bases da Educação Nacional. Lei n. 9.394, de 20/12/1996. & 7 & $26,9 \%$ \\
\hline Estatuto da criança e do adolescente. Lei n. 8.069, de 13/07/1990. & 3 & $11,5 \%$ \\
\hline Resolução no 196, de 10/10/1996. Conselho Nacional de Saúde. & 3 & $11,5 \%$ \\
\hline $\begin{array}{l}\text { Política Nacional de Humanização: humanização da atenção e da gestão em } \\
\text { saúde do Sistema Único de Saúde. Ministério da Saúde, 2004. }\end{array}$ & 2 & $7,7 \%$ \\
\hline
\end{tabular}

Fonte: pesquisa dos autores

\section{CONCLUSÕES}

Os princípios legais que garantem o atendimento pedagógico a educandos em processo de tratamento de saúde continuam valendo em todo território nacional, apesar da atual política de educação especial do MEC não contemplar tais ações como foco de atenção. Embora não haja um reflexo direto, a produção do conhecimento que abarca essa temática tem demonstrado certa estagnação, não havendo no último quinquênio nenhum artigo referendado nas bases pesquisadas.

Os 26 artigos analisados no contexto do estudo encontraram-se publicados em 19 periódicos distintos, com divisão equilibrada nas áreas de educação e saúde, áreas de confluência do tema em estudo. Tais fatores demonstram que não há um direcionamento específico das publicações encaminhadas.

A predominância dos estudos sobre classe hospitalar, verificado por meio do levantamento dos objetivos, deu-se nas atividades de formação de docentes, principalmente de pedagogos, e a sondagem sobre a percepção dos familiares e acompanhantes, a respeito da escolarização oferecida no ambiente hospitalar.

A maioria das publicações correspondem a estudos baseados no método qualitativo e em registros de experiências e reflexões sobre estas. As universidades federais se apresentam como espaço institucional com a maior produção dos artigos sobre classe hospitalar, em particular aquelas situadas na região sul do país. 
A indicação das principais referências adotadas, bem como os principais referendos que fundamentam a base documental dos estudos, fornece um rol exemplificativo da concentração da produção relativa à classe hospitalar. Esse panorama possibilita um melhor embasamento teórico-metodológico em estudos sobre o tema.

Portanto, entendendo que a produção do conhecimento representa uma das principais atividades do meio acadêmico, e que esse conhecimento é fundamental na efetivação de mudanças na esfera social, ao realizarmos um levantamento da produção científica esperamos apreender como determinado tema é abordado e, consequentemente, perceber as preocupações (ou ausência destas) em relação a esse assunto. Em nosso caminhar, propusemo-nos contribuir com a área, fundamentando bases para novas pesquisas.

\section{REFERENNCIAS}

ANDRÉ, Marli E. D. A. A pesquisa sobre formação de professores no Brasil: 1990/98. In: CANDAU, V. M. (org.) Ensinar e aprender: sujeitos, saberes e pesquisa (Endipe). Rio de Janeiro, DP\&A, 2000, p.

ANDRÉ, Marli E. D. A. Pesquisa em Educação: buscando rigor e qualidade. Cadernos de pesquisa, n. 113, p. 51-64, julho/ 2001.

ALBERTONI, Léa Chuster. A inclusão escolar de alunos com doenças crônicas: professores e gestores dizem que... Curitiba: Ed. Appris, 2014

BARros, A. S. S.; GUEUDEVILLE, R. S.;VIEIRA, S. C. Perfil da publicação científica brasileira sobre a temática da classe hospitalar. Revista Brasileira de Educação Especial, Marília, vol.17, n.2, pp. 335-354, mai./ago. 2011.

BAUER, Martin W.; GASKELL, George. Pesquisa qualitativa com texto, imagem e som: um manual prático. Trad. Pedrinho A. Guareschi. Petrópolis, RJ, Vozes, 2002.

BRASIL. Política Nacional de Educação Especial na perspectiva da Educação Inclusiva. Brasília: MEC/SEESP, 2008.

BRASIL. Ministério da Educação. Classe hospitalar e atendimento pedagógico domiciliar: estratégias e orientações. Secretaria de Educação Especial. Brasília: MEC/SEESP, 2002.

442 - RBPAE - v. 33, n. 2, p. 421 - 447, mai./ago. 2017 
BRASIL. Diretrizes Nacionais para a Educação Especial na Educação Básica. Resolução CNE/CBE no 02 de 11 de setembro de 2001. Diário Oficial da União n. 177, Seção 1E de 14/09/01, pp.39-40. Brasília: Imprensa Oficial, 2001.

BRASIL. Decreto n. 3.298 de 20 de dezembro de 1999. Dispõe sobre a política nacional de integração da pessoa portadora de deficiência. Presidência da República. Casa Civil. Ministério da Educação, 1999.

BRASIL. Lei no 9.394, de 20 de dezembro de 1996. Estabelece as diretrizes e bases da educação nacional. Diário Oficial [da] República Federativa do Brasil, Brasília, 23 de dez. 1996. Seção 1. 1996.

BRASIL. Ministério da Educação. Política Nacional de Educação Especial. Secretaria de Educação Especial. Brasília: MEC/SEESP. Brasília, DF, 1994.

BRASIL. Lei n. 8.069, de 13 de julho de 1990. Dispõe sobre o Estatuto da Criança e do Adolescente. Brasília, 1990.

BRASIL. Constituição. Constituição da República Federativa do Brasil: promulgada em 5 de outubro de 1988. 35. Brasília, 1988.

CONANDA. Conselho Nacional dos Direitos da Criança e do Adolescente (Brasil). Resoluções, junho de 1993 a setembro de 2004. Resolução n. 42, de 13 de outurbro de 1995. Secretaria Executiva do Conanda. Brasília: Secretaria Especial dos Direitos Humanos, 2004. 200 p.

FONSECA, E. S. A situação brasileira do atendimento pedagógico-educacional hospitalar. Educação e Pesquisa, São Paulo, v. 25, n. 1, pp. 117-129, jan./jun. 1999.

GAT'TI, Bernardete A. A produção da pesquisa em educação no Brasil e suas implicações socio-político-educacionais: uma perspectiva da contemporaneidade. Campinas, SP, 2000. Trabalho apresentado na III Conferência de Pesquisa Sociocultural.

XAVIER, T. G. M. et al. Classe hospitalar: Produção do conhecimento em saúde e educação. Revista Brasileira de Educação Especial, Marília, vol. 19, n. 4, pp. 611-622, out./dez. 2013. 
Apêndice: referência dos artigos da revisão sistemática

ALBERTONI, L. C.; GOULART, B. N. G.; CHIARI, B. M. Implantação de classe hospitalar em um hospital público universitário de São Paulo. Revista Brasileira de Crescimento e Desenvolvimento Humano, São Paulo, vol. 21, n. 2, pp. 362-367, 2011.L

BARROS, A. S. S.; GUEUDEVILLE, R. S.; VIEIRA, S. C. Perfil da publicação científica brasileira sobre a temática da classe hospitalar. Revista Brasileira de Educação Especial, Marília, vol.17, n.2, pp. 335-354, mai./ago. 2011.

BARROS, A. S. S. Contribuições da educação profissional em saúde à formação para o trabalho em classes hospitalares. Cadernos CEDES, Campinas, vol. 27, n. 73, pp. 257-278, set./dez. 2007.

CARDOSO, T. M. Experiências de ensino, pesquisa e extensão no setor de Pedagogia do HIJG. Cadernos CEDES, Campinas, vol. 27, n. 73, pp. 305-318, set./dez. 2007.

FERREIRA, M. K. M. Criança e adolescente cronicamente adoecidos e a escolarização durante a internação hospitalar. Trabalho, Educação e Saúde, Rio de Janeiro, vol. 13, n. 3, pp. 639-655, set./dez. 2015.

FREITAS, S. N. et al. Inteligências Múltiplas: Desenvolvendo potencialidades em classe hospitalar. Educação, Porto Alegre, vol. 28, n. 1, pp. 101-115, jan./abr. 2005.

HOLANDA, E. R.; COLLET, N. As dificuldades da escolarização da criança com doença crônica no contexto hospitalar. Revista da Escola de Enfermagem da USP, São Paulo, vol. 45, n. 2, pp. 381-389, 2011.

HOLANDA, E. R.; COLLET, N. Escolarização da criança hospitalizada sob a ótica da família. Revista Texto \& Contexto Enfermagem, Florianópolis, vol. 21, n. 1, pp. 34-42, jan./mar. 2012.

HOSTERT, P. C. C. P.; ENUMO, S. R. F.; LOSS, A. B. M. Brincar e problemas de comportamento de crianças com câncer de classes hospitalares. Revista Psicologia: Teoria e Prática, São Paulo, vol. 16, n. 1, pp. 127-140, jan./abr. 2014. 
HOSTERT, P. C. C. P.; MOT'TA, A. B.; ENUMO, S. R. F. Coping da hospitalização em crianças com câncer: A importância da classe hospitalar. Estudos de Psicologia, Campinas, vol. 32, n. 4, pp. 627-639, out./dez. 2015.

INVERNIZZI, L.; VAZ, A. F. Educação Física nos primeiros anos do ensino fundamental: Uma pesquisa sobre sua organização pedagógica em classe hospitalar. Movimento, Porto Alegre, vol. 14, n. 2, pp. 115-132, mai./ago. 2008.

LIMA, M. C. C.; NATEL, M. C. A psicopedagogia e o atendimento pedagógico hospitalar. Revista Psicopedagogia, São Paulo, vol. 27, n. 82, pp. 127-139, 2010.

LINHEIRA, C. Z.; CASSIANI, S.; MOHR, A. Desafios para o ensino de ciências na classe hospitalar: Relato de uma pesquisa e ensino na formação de professores. Ciência \& Educação, Bauru, vol. 19, n. 3, pp. 535-554, 2013.

MAZER, S. M.; TINÓS, L. M. S. A educação especial na formação do pedagogo da classe hospitalar: Uma questão a ser discutida. Revista Educação Especial, Santa Maria, vol. 24, n. 41, pp. 377-390, set./dez. 2011.

NOFFS, N. A.; RACHMAN, V. C. B. Psicopedagogia e saúde: Reflexões sobre a atuação psicopedagógica no contexto hospitalar. Revista Psicopedagogia, São Paulo, vol. 24, n. 74, pp. 160-168, 2007.

ORTIZ, L. C. M. et al. A classe hospitalar como instrumento de participação política na construção coletiva da Associação de Pais e Pacientes da HematoOncologia. Educação em Revista, Belo Horizonte, vol. 26, n. 2, pp. 317-336, ago. 2010

ORTIZ, L. C. M.; FREITAS, S. N. O currículo da Classe Hospitalar Pioneira no Rio Grande do Sul. Educação \& Realidade, Porto Alegre, vol. 39, n. 2, pp. 595 616, jun. 2014.

PAULA, E. M. A. T. Crianças e adolescentes que voam em jaulas: A tecnologia promovendo a liberdade no hospital. Cadernos CEDES, Campinas, vol. 27, n. 73, pp. 319-334, set./dez. 2007.

ROLIM, C. L. A.; GÓES, M. C. R. Crianças com câncer e o atendimento educacional nos ambientes hospitalar e escolar. Educação e Pesquisa, São Paulo, vol. 35, n. 3, pp. 509-523, set./dez. 2009. 
SOUZA, A. M. A formação do Pedagogo para o trabalho no contexto hospitalar: A experiência da Faculdade de Educação da UnB. Linhas Críticas, Brasilia, vol. 17, n. 33, pp. 251-272, mai./ago. 2011.

TOMASINI, R. O diálogo como estratégia das ações educativas no hospital: $\mathrm{O}$ pedagogo hospitalar e alguns saberes e fazeres. Zona Próxima, Barranquilla, n. 8, pp. 62-77, dez. 2007.

VASCONCELOS, S. M. F. Histórias de formação de professores para a Classe Hospitalar. Revista Educação Especial, Santa Maria, vol. 28, n. 51, pp. 27-40, jan./abr. 2015.

VAZ, A. F.; VIEIRA, C. L. N.; GONÇALVES, M. C. Educação do corpo e seus limites: Possibilidades para a Educação Física na classe hospitalar. Movimento, Porto Alegre, vol. 11, n. 1, pp. 71-87, jan./abr. 2005.

XAVIER, T. G. M. et al. Classe hospitalar: Produção do conhecimento em saúde e educação. Revista Brasileira de Educação Especial, Marília, vol. 19, n. 4, pp. 611-622, out./dez. 2013.

ZARDO, S. P.; FREITAS, S. N. Educação em classes hospitalares: transformando ações e concepções à luz da teoria da complexidade. Educar em revista, Curitiba, n. 30, pp. 185-196, 2007.

ZOMBINI, E. V. et al. Classe hospitalar: A articulação da saúde e educação como expressão da política de humanização do SUS. Trabalho, Educação e Saúde, Rio de Janeiro, vol. 10, n. 1, pp. 71-86, mar./jun. 2012..

RICARDO ANTONIO GONÇALVES TEIXEIRA, licenciatura em matemática e pedagogia, bacharel em administração, mestrado e doutorado na área de educação. Pós-Doutorado em Tecnologias de Investigação pelo Departamento de Educação da Universidade de Aveiro (UA) Pt; pós-doutorado em Tecnologias Assistivas pela Faculdade de Engenharia Elétrica da Universidade de Uberlâdia, Minas Gerais (UFU); pós-doutorado pelo Programa Avançado de Culturas Contemporâneas da Universidade Federal do Rio de Janeiro, Rio de Janeiro (UFRJ); pós-doutorado em Educação Inclusiva e Saúde Coletiva pela Faculdade de Ciências Médicas da Universidade de Campinas, São Paulo (Unicamp). Professor da Faculdade de Educação e Programa de Pós-Graduação em Educação da Universidade Federal de Goiás (UFG). E-mail: professorricardoteixeira@ gmail.com 
UYARA SOARES CAVALCANTI TEIXEIRA, licenciatura em matemática, bacharel em engenharia civil, especialização em práticas pedagógicas e engenharia de segurança do trabalho. Mestranda em matemática pelo Programa de Mestrado Profissional em Matemática (PROFMAT) do Instituto de Matemática e Estatística da Universidade Federal de Goiás (UFG), em parceria com o Instituto de Matemática Pura e Aplicada (IMPA). Professora da rede estadual de educação de Goiás e do Núcleo de Atendimento Educacional Hospitalar (NAEH), órgãos da Secretaria de Estado da Educação, Cultura e Esporte de Goiás (SEDUCE). E-mail: uyras@gmail.com

MÁRIO JOSÉ DE SOUZA, mestrado em Matemática pela Universidade Federal de Goiás (2000) e doutorado em Engenharia Elétrica, pela Universidade de Campinas (Unicamp). Professor do Instituo de Matemática e Estatística, professor e coordenador do Programa de Mestrado Profissional em Matemática (PROFMAT) da Universidade Federal de Goiás (UFG). E-mail: mariojsouza@, mat.ufg.br

PEDRO PAULO PEREIRA RAMOS, Licenciado em Pedagogia pela Faculdade de Educação da Universidade Federal de Goiás. Professor da rede estadual de Educação órgão da Secretaria de Estado da Educação, Cultura e Esporte de Goiás (SEDUCE), Goiás. Participante do Grupo de Estudos e Pesquisas em Educação, Saúde e Inclusão. E-mail: ramospedropaulo@hotmail.com.br

Recebido em janeiro de 2017 Aprovado em fevereiro de 2017 